\title{
A new model \\ of equilibrium involuntary unemployment ${ }^{\star}$
}

\section{Leo Kaas ${ }^{1}$ and Paul Madden ${ }^{2}$}

1 Department of Economics, University of Vienna, Hohenstaufengasse 9, 1010 Vienna, AUSTRIA (e-mail: leo.kaas@univie.ac.at)

2 School of Economic Studies, Manchester University, Manchester M13 9PL, UK (e-mail: Paul.Madden@man.ac.uk)

Summary. We show that equilibrium involuntary unemployment emerges in a multi-stage game model where all market power resides with firms, on both the labour and the output market. Firms decide wages, employment, output and prices, and under constant returns there exists a continuum of subgame perfect Nash equilibria involving unemployment and positive profits. A firm does not undercut the equilibrium wage since then high wage firms would attract its workers, thus forcing the undercutting firm out of both markets. Full employment equilibria are payoff dominated by unemployment equilibria, and the arguments are robust to decreasing returns.

Keywords and Phrases: Involuntary unemployment, Multi-stage game, Imperfect competition.

JEL Classification Numbers: D43, E24.

* We thank an anonymous referee, Woojin Lee, Klaus Ritzberger and seminar participants in Konstanz, Manchester, Milan, Prague, Vienna, and Warwick for helpful comments. Financial support from the Economic and Social Research Council (UK) under grant L138251030 and from the Manchester School Visiting Fellowship Scheme is gratefully acknowledged.

Correspondence to: L. Kaas 


\section{Introduction}

This paper provides a new explanation for involuntary unemployment as an equilibrium phenomenon under imperfect competition. We consider an oligempory ${ }^{1}$ market structure, modelled as a multi-stage game, in which all market power resides with firms; the same set of firms are wage-setting oligopsonists in their homogeneous labour market and price-setting oligopolists in their homogeneous output market. Equilibrium involuntary unemployment emerges in a novel way, driven essentially by a Bertrand mechanism, and yet with positive profits and robustness to decreasing returns. Firms do not undercut the unemployment wage since they fear that competitors expand labour demand, leaving the undercutter with zero employment and profit.

Motivated in parts by Roberts $(1987,1989)$ and Jones and Manuelli (1992), the oligempory is modelled as a four-stage game with $n(\geq 3)$ firms facing an upwardsloping labour supply function and a downward-sloping elastic output demand function; implicitly these functions emanate from decisions of a large (competitive) number of workers and consumers, so that firms possess all the market power on both labour and output markets. As in the previous literature we assume that firms precommit to announcing wages (stage I). Thereafter, and unlike the predecessors, firms make labour demand decisions which (via a rationing mechanism) determine employment levels (stage II), output is produced (stage III) and output prices are announced (stage IV). This sequence seems natural for a "produce for inventory" industry where firms employ many homogeneous workers. Plausibly such firms post or advertise the wage on offer (stage I) prior to any commitment on the employment level at this wage (stage II); then output is produced (stage III) and the stock of output is "taken to the market" where price decisions are made (stage IV). The results are that, under constant returns the Walrasian equilibrium is a subgame perfect Nash equilibrium, but there also exists a continuum of subgame perfect Nash equilibria involving involuntary unemployment in which firms earn strictly positive profits and which therefore payoff dominate the zero-profit competitive equilibrium. Moreover, the existence of a continuum of involuntary unemployment equilibria which payoff dominate any full employment equilibria is robust to small amounts of decreasing returns.

The reason why firms do not undercut a symmetric wage which leads to involuntary unemployment and positive profits is as follows. Take the constant returns case, with "output=input" technologies. Suppose firm 1 undercuts at stage I and suppose that the $n-1$ high wage firms then expand labour demands at stage II so that any $n-2$ of them would exhaust the labour supply at the high wage. Then, at stage II: (i) all the (homogenous) labour supply offered at the high wage is employed, and this will be so even if one of the high wage firms deviates from its assumed large stage II labour demand to any other level; (ii) because a labour demand deviation by any one high wage firm has no impact on aggregate employment, it has no impact on aggregate output (stage III) or its price (stage IV), and if this price,

1 The terms monempory (a single trader) and oligempory (a few traders) were coined by Nichol (1943). An extensive study of oligempory from the industrial organization viewpoint can be found in Dobson (1990). 
as it can, exceeds the high wage it becomes a best response for each high-wage firm to choose the initially assumed high level of labour demand; (iii) irrespective of its labour demand, firm 1 ends up with zero residual labour supply, and gets no workers, no output and no profit. Thus there emerges a stage II continuation after undercutting by firm 1 which leaves firm 1 with zero profits. Moreover, this Bertrand-style conclusion remains under small amounts of decreasing returns. So in our "double-market" model, unlike in the classic Bertrand story, there emerges a continuum of equilibria with rationing of labour supply and with positive profits, and this outcome does not depend in a "knife-edge" way on constant returns.

Our explanation for involuntary unemployment differs from previous explanations as follows.

(a) It is well-known that involuntary unemployment can be generated by exogenous wage/price rigidities (in the so-called disequilibrium literature), efficiency wages (where firms set high wages as it leads to greater productivity), output market power with inelastic product demand (where the competitive wage drops to zero) or trade unions (demanding a wage which is too high for full employment). In our model there are no exogenous restrictions on the wages/prices firms may choose, there are no efficiency wage effects, output demand is elastic, and labour supply is competitive with all labour market power residing with firms on the demand side. $^{2}$ On the other hand, market power of firms in both the output and the labour market are decisive for our results; when the number of firms tends to infinity, unemployment converges to zero and equilibrium wages and prices converge to their Walrasian values. ${ }^{3}$

(b) Closest to ours is the multi-stage game, constant returns model of Roberts $(1987,1989)$ who assumes that firms must precommit to both wages and prices. Subsequent and simultaneous signalling of labour supplies and output demands 4 creates a continuum of involuntary unemployment equilibria at Walrasian prices, again for a Bertrand reason, but quite different from ours - now the undercutting firm's fear is that, having committed to wages and prices, workers and consumers will subsequently move their labour supply and output demand offers to other firms who (at Walrasian prices, under constant returns) will accept them. However, like the classic Bertrand story and unlike ours, the argument depends on constant returns (see Roberts, 1987, p. 872) and the equilibria generate zero profits, thus ceasing to payoff dominate the Walrasian equilibrium. ${ }^{5}$ Moreover, as shown by Jones and Manuelli (1992), the involuntary unemployment disappears if the simultaneity of labour supply and output demands signals is broken.

2 For surveys on the microfoundations of Keynesian unemployment with imperfect competition in labour and product markets, see Dixon and Rankin (1994) and Silvestre (1993).

3 This result is not surprising in the light of related results for general equilibrium economies with wage and price setting firms (see Funk, 1995).

4 In the games of Roberts and Jones and Manuelli, workers and consumers are "players" who signal individual labour supply and output demand offers to firms. In our model, labour supply and output demand are described by continuous functions which may come from a continuum of workers and consumers, and trades on the output and labour market are described by well-behaved rationing schemes.

5 Drèze (1997) shows that similar supply-constrained equilibria at Walrasian prices exist in a more general model (compatible with decreasing returns and positive profits). However, his argument rests on exogenous price rigidities. 
(c) Other explanations of involuntary unemployment equilibrium where firms rationally fail to lower wages are provided by recent theories of reciprocity (e.g. Dufwenberg and Kirchsteiger, 2000) ${ }^{6}$, and the examples of Heal (1981) and Böhm et al. (1983) where price-setting agents impose binding quantity constraints on other agents in equilibrium, because of certain nonconvexities (Heal) or agent heterogeneities (Böhm et al., 1983). ${ }^{7}$ In our model such reciprocities, nonconvexities and heterogeneities are all absent.

On the other hand, there are multi-stage game models of firm interaction which fail to produce our equilibrium with rationing. Crucial features of our model are the strategic links between labour demand decisions and employment determination (stage II) and the subsequent determination of output prices (stage IV). It is the presence of these links which allows high wage firms to credibly coordinate on the increase in their labour demands (after one firm undercuts) which makes undercutting unprofitable, and which is critical for our conclusions. However in Jones and Manuelli (1992) firms precommit to prices at stage I (as in Roberts), and in Stahl (1988) there is no separate labour (=input) ${ }^{8}$ demand decision (inputs being allocated automatically on the usual Bertrand "winner-takes-all" basis), thus absenting these models from our crucial mechanism and leading to their "no equilibrium rationing" conclusions. ${ }^{9}$ And finally, the dynamic oligempory model of Gaygisiz and Madden (2002) focuses on multiple long-run equilibria with heterogeneous labour markets and voluntary unemployment, albeit with a similar market structure to ours.

The paper is organized as follows. In the next section we introduce the model, in Section 3 we show the existence of a continuum of unemployment equilibria in the constant returns case, and in Section 4 we show that the competitive equilibrium is the unique symmetric equilibrium with full employment. Section 5 discusses competitive limits, and in Section 6 we discuss the robustness of our results to variations of the model. Section 7 concludes. Some proofs which are not included in the text are contained in the Appendix.

6 The view that firms may be reluctant to cut wages even in the face of unemployment is also supported by interview studies (e.g. Bewley, 1998) and by experimental labour market studies (e.g. Fehr et al., 1993, 1998).

7 Of course there are many models where the equilibrium actions of agents with market power on one side of a market lead to no rationing of the other side of the market but to implicit rationing of their own trades; see Madden and Silvestre $(1991,1992)$ for a discussion of the relation between some of these models and fixprice equilibria.

8 In Stahl's model firms are "middlemen" making a market by buying from suppliers before selling to purchasers - but one may equivalently think of firms buying labour input, producing output under constant returns and selling output to the demanders.

9 Stahl's model may also generate a non-Walrasian conclusion under inelastic demand. If at equal input prices it is assumed that a "winner" is randomly selected, the winner will take all the supply (so there is still no rationing) but may retain some of this as unsold stock to force up output price at the second stage. See also Yanelle (1989). 


\section{The model}

The setup

There are $n \geq 3$ profit-maximizing firms producing a homogeneous output good from inputs of homogeneous labour under, for now, unit constant returns. ${ }^{10}$ So each firm's technology is $y_{i} \leq f\left(\ell_{i}\right)=\ell_{i}$, where $y_{i}$ denotes output and $\ell_{i}$ labour input of firm $i=1, \ldots, n$. These firms face a supply of labour function $S(w)$ and a demand for output function $D(p)$ which are both assumed to be differentiable such that $S^{\prime} \geq 0>D^{\prime}$ whenever these functions are defined and positive. We assume that there is a unique positive Walrasian equilibrium wage (=price) $w^{*}=p^{*}>0$ such that $S\left(w^{*}\right)=D\left(p^{*}\right)>0$. The supply of labour is assumed to be bounded, $S(w) \leq \bar{S}$. It is assumed that the inverse demand function $P=D^{-1}$ is defined and positive on the domain $0<Y<\bar{S}$, and that the revenue function $P(Y) Y$ is strictly concave, i.e.

$$
P^{\prime \prime}(Y) Y+2 P^{\prime}(Y)<0 \quad, 0<Y<\bar{S} .
$$

We further assume that the revenue function is increasing, or equivalently that demand is elastic:

$$
\operatorname{MR}(Y) \equiv P^{\prime}(Y) Y+P(Y)>0 \quad, 0<Y<\bar{S} .
$$

Moreover, we assume $\operatorname{MR}(0)=P(0)$ (which may be infinity). Obvious examples of demand functions satisfying these requirements are the uniformly elastic demand functions $D(p)=A p^{-\alpha}, \alpha>1$, or the linear demand functions $D(p)=a-b p$ provided that $\bar{S} \leq a / 2$.

\section{The game}

We will analyze a game between firms which has four stages. All actions are taken simultaneously at each stage and firms are perfectly informed of past actions. ${ }^{11}$ Firms set wages at stage I, decide on employment at stage II and on production at stage III, and they set output prices at stage IV. After firms announce wages $w_{1}, \ldots, w_{n}$ at stage I, labour would be supplied first to the highest wage firms, but these firms need not want to employ all labour supplied to them. Instead, at stage II firms decide on employment by signalling labour demands (or job offers) $J_{1}, \ldots, J_{n} \geq 0$ to the market. If now labour demand of the highest wage firms falls short of labour supply at that wage, the latter is rationed and some residual labour supply spills over to the firms setting the second highest wage. We assume that labour supply is efficiently rationed (see e.g. Kreps and Scheinkman 1983; Osborne and Pitchik, 1986). That is, if labour supply at the highest wage is $S\left(w^{H}\right)$ and total labour demand of the highest wage firms is $J^{H}<S\left(w^{H}\right)$, then residual

10 Most of our results extend to $n=2$ firms as well, but require slightly different proofs. Thus we assume $n \geq 3$ for convenience and refer to the two-firms case when necessary.

11 Though an extension of our model to an environment of a repeated game with imperfect information would be interesting, it is beyond the scope of this paper. 
labour supply at the second highest wage $w^{L}<w^{H}$ is $\max \left(0, S\left(w^{L}\right)-J^{H}\right)$. Similarly, labour supply is efficiently rationed at all other wages. ${ }^{12}$

If, on the other hand, there is an excess demand for labour at some wage, firms are rationed. Specifically, if $J_{1}, \ldots, J_{m}$ are the labour demands of firms setting the same wage and if $S$ is the (residual) labour supply at that wage, labour is allocated to the firms via a rationing scheme which satisfies

$$
\ell_{i}=\min \left(J_{i}, c\left(\left(J_{k}\right)_{k=1, \ldots, m, k \neq i}, S\right)\right), i=1, \ldots, m,
$$

where the continuous function $c: \mathbb{R}_{+}^{m} \rightarrow \mathbb{R}_{+}$defines employment constraints for all firms. Thus, we are assuming that the rationing scheme is non-manipulable (i.e. the employment constraint of each firm does not depend on its own demand) and symmetric (i.e. employment constraints are identical functions for all firms). Moreover, we assume that rationing is frictionless (i.e. only one side of the market is rationed, $\left.\sum_{i=1}^{m} \ell_{i}=\min \left(\sum_{i=1}^{m} J_{i}, S\right)\right) .{ }^{13}$ An important consequence of these assumptions (see Lemma A.1 in the Appendix) is that if $m-1$ of these firms offer the same labour demand ( $J$ say) then the employment constraint facing the remaining firm is

$$
c(J, \ldots, J, S)=\max \left(\frac{S}{m}, S-(m-1) J\right) .
$$

After firms pay the wage bill $w_{i} \ell_{i}$ at the end of stage II, they decide on production $y_{i} \leq \ell_{i}$ at stage III, and at stage IV they set output prices $p_{1}, \ldots, p_{n}$. Stage IV thus becomes a Bertrand-Edgeworth game with "capacities" $\left(y_{1}, \ldots, y_{n}\right)$ in which costs are sunk.

\section{The stage III and stage IV equilibrium}

Because demand is elastic, there are unique Nash equilibrium payoffs to the stage IV subgame which are those that emerge from the firms setting the market clearing price:

$$
p_{1}=\ldots=p_{n}=P\left(y_{1}+\ldots+y_{n}\right) .
$$

Unlike Kreps and Scheinkman (1983), this result does not depend on the way consumers' demand is rationed at asymmetric prices (i.e. according to the efficient or the random rationing rule) and ensures that the Bertrand price setting produces an essentially Cournot outcome (see Madden, 1998). Also because demand is elastic, each firm's revenue $P\left(y_{i}+y_{-i}\right) y_{i}$ is strictly increasing, and thus the unique subgame perfect Nash equilibrium of each stage III subgame is that firms produce at their capacity level

$$
y_{i}=\ell_{i} \quad, i=1, \ldots, n .
$$

12 The robustness of our results to the random (also Beckman or proportional) rationing rule (Beckmann, 1965; Allen and Hellwig, 1986) will be discussed in Section 6.

13 The uniform rationing scheme (see Benassy (1982, Appendix J)) is an example of a rationing scheme satisfying our assumptions. Non-manipulability is a decisive feature to guarantee existence of equilibrium, see also our discussion in Section 6. 
We are interested in the set of symmetric equilibria of this game, which are defined as subgame perfect Nash equilibria in which firms play equal pure strategies at each stage along the equilibrium path. Given the subgame perfect Nash continuations of the stage III and stage IV subgames noted in (5) and (6), it remains to consider the 2-stage game in wages $\left(w_{1}, \ldots, w_{n}\right)$ (stage I) and labour demands $\left(J_{1}, \ldots, J_{n}\right)$ (stage II).

\section{Unemployment equilibria}

We start the analysis by considering the Nash equilibria of the second stage game following symmetric wages $w_{1}=\ldots=w_{n}=w$ at stage I. Naturally, if the wage is sufficiently large, there are stage II Nash equilibria with involuntary unemployment (rationing of labour supply), and we show later on that some of these wages followed by their unemployment stage II continuation are in fact subgame perfect. For this it is sufficient to show that neither an undercutting nor an overbidding by any firm (say firm 1) can be profitable. Thus we have to show that both the stage II subgames following wages $w_{1}>w_{2}=\ldots=w_{n}=w$ and $w_{1}<w_{2}=\ldots=w_{n}=w$ have stage II Nash equilibrium continuations which give the deviating firm 1 a profit not larger than its profit at the symmetric wage $w_{1}=\ldots=w_{n}=w \cdot{ }^{14}$ Our arguments refer at various points to the following Cournot Nash equilibrium levels of labour demand. Given $w_{1}, \ldots, w_{n}$, the Cournot best response problem is (ignoring labour supply constraints)

$$
\max _{\ell_{i}} P\left(\ell_{1}+\ldots+\ell_{n}\right) \ell_{i}-w_{i} \ell_{i} \quad \text { s.t } \quad \ell_{i} \geq 0
$$

The objective is strictly concave in $\ell_{i}$ by assumption (1), and the Cournot Nash equilibrium levels of labour demand (at $w_{1}, \ldots, w_{n}$ ) are Nash equilibria of the game with payoffs given by (7).

\section{Symmetric wage subgames}

Suppose firms announce equal wages $w_{1}=\ldots=w_{n}=w$ at stage $\mathrm{I}$. The first order conditions for an interior $\left(\ell_{i}>0\right.$ for all $\left.i\right)$ Cournot Nash equilibrium are

$$
P^{\prime}\left(\ell_{1}+\ldots+\ell_{n}\right) \ell_{i}+P\left(\ell_{1}+\ldots+\ell_{n}\right)=w \quad, i=1, \ldots, n .
$$

It follows immediately that any interior Cournot Nash equilibrium is symmetric, $\ell_{i}=L / n$, where $L$ satisfies

$$
\Psi(L) \equiv P^{\prime}(L) \frac{L}{n}+P(L)=w .
$$

14 We do not consider the other (irrelevant) subgames at asymmetric wages, but we notice that since the payoffs are continuous in $\left(J_{1}, \ldots, J_{n}\right) \in[0, \bar{S}]^{n}$, Glicksberg's Theorem (see Fudenberg and Tirole, 1991) implies that there exists a Nash equilibrium of any stage II subgame, at least in mixed strategies. 


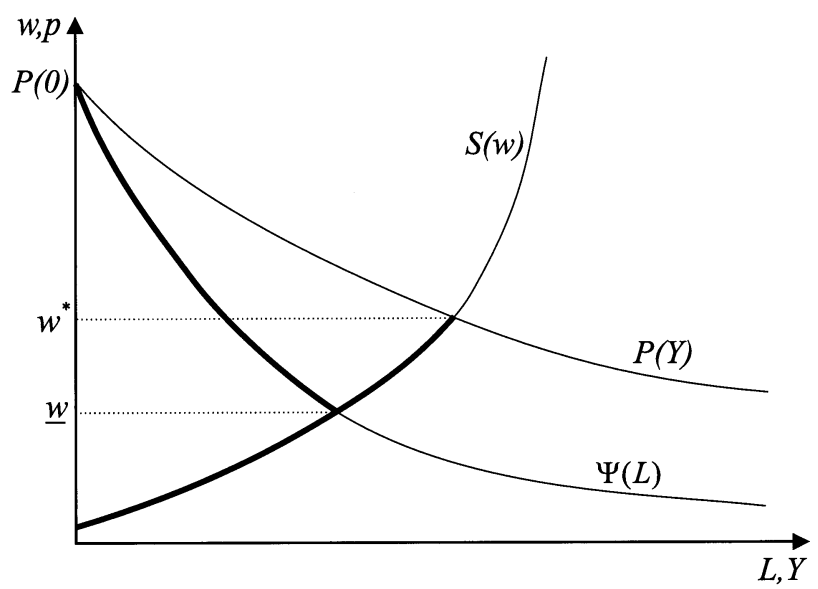

Figure 1. The supply, demand, and Cournot equilibrium curves. The bold curves indicate stage II Nash equilibrium employment after symmetric wages at stage I

(1) and (2) imply that $\Psi^{\prime}(L)<0$ and $0<\operatorname{MR}(L)<\Psi(L)<P(L)$ for all $0<L<\bar{S}$, and thus also $\Psi(0)=P(0)$. Hence, there exists a unique positive wage $\underline{w}<w^{*}$ such that $\Psi(S(\underline{w}))=\underline{w}$, and so $L=\Psi^{-1}(w)<S(w)$ for all $\underline{w}<w<P(0)$ (see Fig. 1). Therefore, any Cournot Nash equilibrium at a wage $\bar{w}>\underline{w}$ involves an excess supply of labour and thus provides a candidate for an unemployment equilibrium at stage II in our model. And of course, since price exceeds the wage all these Cournot Nash equilibria involve positive profits.

It is now straightforward to see that the Cournot Nash employment levels $\ell=$ $\Psi^{-1}(w) / n$ are also Nash equilibrium strategies of the original stage II game in labour demands $J_{1}, \ldots, J_{n}$ provided that $w>\underline{w}$. Since the rationing scheme is non-manipulable and symmetric, the employment constraint facing each firm is $c=S(w)-(n-1) \ell$ given that all firms signal Cournot Nash labour demands (see (4)). If firm 1 deviated from the Cournot Nash labour demand to some $J_{1}$, its employment level would be $\ell_{1}=\min \left(J_{1}, c\right)$ and the employment levels of all other firms would remain unchanged; thus, firm 1 would make a strictly lower profit. This implies

Proposition 1. If firms set equal wages $w_{1}=\ldots w_{n}=w \in(\underline{w}, P(0))$ at stage I, there is a Nash equilibrium of the stage II game with involuntary unemployment and positive profits in which firms' labour demands and employment levels are

$$
J_{1}=\ldots=J_{n}=\ell_{1}=\ldots=\ell_{n}=\ell=\Psi^{-1}(w) / n<S(w) / n
$$

The bold part of the curve $\Psi$ in Figure 1 shows the unemployment equilibria of Proposition 1. We are now going to show that some of these wages followed by their stage II Nash equilibrium continuation of Proposition 1 are subgame perfect, and for this we show that neither undercutting nor overbidding is profitable. 


\section{Undercutting is unprofitable}

Suppose that firm 1 undercuts at stage I to some $w_{1}<w_{2}=\ldots=w_{n}=w$ where $w>\underline{w}$. Then, as explained in the introduction, the other firms credibly expand their labour demands so as to force the undercutting firm 1 out of both markets, provided that their wage is no higher than the competitive wage. More precisely, if $w \leq w^{*}$ there exists a Nash equilibrium of the stage II game in which all firms $i>1$ signal labour demands $S(w) /(n-2)$ and in which firm 1's labour demand is any arbitrary $J_{1} \geq 0$. Since there is an excess labour demand at the highest wage, employment constraints of all firms $i>1$ are $S(w) /(n-1)$ (see (4) with $m=n-1)$, and so all high wage firms are rationed to $S(w) /(n-1)$. The residual labour supply to firm 1 is zero, and hence firm 1 gets zero employment irrespective of its labour demand. Thus, any $J_{1} \geq 0$ is a best response to $J_{i}=S(w) /(n-2)$, $i>1$. On the other hand, $J_{i}=S(w) /(n-2)$ is also a best response, since for any other labour demand of firm $i$ there would still be an excess demand for labour at the wage $w$, and thus aggregate employment would remain at $S(w)$ and the resulting output price would stay constant at $p=P(S(w))$. Hence firm $i$ 's profit is $(P(S(w))-w) \min \left(J_{i}, S(w) /(n-1)\right)$ which is (when $\left.w \leq w^{*}\right)$ non-decreasing and constant for $J_{i} \geq S(w) /(n-1)$. Therefore, $J_{i}=S(w) /(n-2)$ is a best response to $J_{1}$ and $J_{k}=S(w) /(n-2), k>1, k \neq i$. This proves ${ }^{15}$

Proposition 2. If firms set wages $w_{1}<w_{2}=\ldots=w_{n}=w \in\left(\underline{w}, w^{*}\right]$ at stage I, there exists a Nash equilibrium of the stage II game in which firms' labour demands and employment levels are

$$
\begin{aligned}
& J_{1} \geq 0, J_{2}=\ldots=J_{n}=S(w) /(n-2) \quad \text { and } \\
& \ell_{1}=0, \ell_{2}=\ldots=\ell_{n}=S(w) /(n-1) .
\end{aligned}
$$

In particular, firm 1 makes zero profit and thus undercutting from $w_{1}=\ldots=$ $w_{n}=w$ is unprofitable.

Firms do not undercut because of the credible fear that, at stage II, high wage firms would then expand their labour demands, employment and output so as to reduce the undercutter to zero trades and profits. We remark that there may also be a stage II Nash equilibrium after undercutting which corresponds to the Cournot Nash labour demands at these asymmetric wages. In the following we use the Cournot Nash labour demands at asymmetric wages to argue that overbidding is unprofitable in some cases.

\section{Overbidding is unprofitable}

Suppose now that firm 1 overbids at stage I to $w_{1}>w_{2}=\ldots=w_{n}=w \in$ $\left(\underline{w}, w^{*}\right]$. Lemma A.2 in the Appendix shows that there exists then a Cournot Nash

15 When there are $n=2$ firms, a Nash equilibrium which gives zero profits to the undercutting firm 1 would be $J_{1}=J_{2}=S(w)$. This Nash equilibrium requires that the undercutting firm signals also a high labour demand. 
equilibrium at these wages in which $\ell_{1} \geq 0, \ell_{2}=\ldots=\ell_{n}=\ell>0$ and where there is unemployment at both wages: $\ell_{1}<S\left(w_{1}\right)$ and $(n-1) \ell<S(w)-\ell_{1}$, and so this Cournot Nash equilibrium provides a candidate for a stage II unemployment equilibrium. Moreover, firm 1's profit $\pi_{1}\left(w_{1}, w\right)$ at this Cournot Nash equilibrium is strictly decreasing in $w_{1}$ whenever it is positive, and may possibly become zero when $w_{1}$ is large. Therefore, firm 1's profit at the Cournot Nash equilibrium after $w_{1}>w$ is lower than its profit $\pi_{1}(w, w)$ at the symmetric wage outcome of Proposition 1. We are now going to show that the Cournot Nash equilibrium at $\left(w_{1}, w\right)$ is indeed a stage II Nash equilibrium of our game in labour demands, provided that the wage $w$ is not too low (or equivalently that there is sufficiently high unemployment at the equilibrium wage), thus establishing that overbidding is unprofitable. On the other hand, if the wage (and unemployment) is too low, it becomes profitable for the overbidding firm to employ all labour, so as to force other firms out of both markets. Thus, only at sufficiently high wages (unemployment levels) firms do not want to overbid the equilibrium wage in order to corner the output market.

Consider first the best response problem of low wage firms $i=2, \ldots, n$ at stage II. If $J_{1}=\ell_{1}$, the residual labour supply at the low wage $w$ is $S=S(w)-\ell_{1}$. By (4) (with $m=n-1$ ), the employment constraints facing firms $2, \ldots, n$ are $S-(n-2) \ell$ when all these firms signal the Cournot Nash labour demands $J_{i}=\ell$, $i>1$. Therefore, to signal any other labour demand cannot change employment of the other firms, and is therefore not profitable. Hence, the Cournot Nash labour demand $J_{i}=\ell$ is a best response for any low wage firm $i>1$ when $J_{1}=\ell_{1}$ and $J_{k}=\ell, k>1, k \neq i$.

Consider now the best response problem of the overbidding firm 1 . If $J_{i}=\ell$ for all $i>1, J_{1}=\ell_{1}$ is clearly the best response amongst all $J_{1}<S(w)-(n-1) \ell$ since for these labour demands no firm is rationed. Suppose however that firm 1 raises its labour demand to some $J_{1} \in[S(w)-(n-1) \ell, S(w)]$. Because $J_{1}<$ $S\left(w_{1}\right)$, firm 1 would not be rationed and would employ $J_{1}$, but firms $i>1$ would be symmetrically rationed to $\tilde{\ell}=\left(S(w)-J_{1}\right) /(n-1)$. Total employment would thus be $J_{1}+(n-1) \tilde{\ell}=S(w)$ and the output price would be $P(S(w))$. Hence, firm 1's profit at any such $J_{1}$ would be less than or equal to

$$
\hat{\pi}_{1}\left(w_{1}, w\right) \equiv \max \left\{\left(P(S(w))-w_{1}\right) J_{1} \text { s.t. } 0 \leq J_{1} \leq S(w)\right\} .
$$

If firm 1 raised its labour demand to some $J_{1}>S(w)$, all firms $i>1$ would be rationed to zero, and firm 1 would employ $\ell_{1}=\min \left(J_{1}, S\left(w_{1}\right)\right)$ and make profit $\pi\left(\ell_{1}\right)=\left(P\left(\ell_{1}\right)-w_{1}\right) \ell_{1}$. This profit is decreasing in $\ell_{1} \geq S(w)$ and hence non-increasing in $J_{1} \geq S(w)$ since

$$
\pi^{\prime}\left(\ell_{1}\right)=\operatorname{MR}\left(\ell_{1}\right)-w_{1}<\Psi\left(\ell_{1}\right)-w_{1} \leq \Psi(S(w))-w_{1}<w-w_{1}<0 .
$$

Thus, firm 1 makes a lower profit than $\hat{\pi}_{1}\left(w_{1}, w\right)$ by signalling a labour demand $J_{1}>S(w)$.

Notice that $\hat{\pi}_{1}\left(w_{1}, w\right)=0$ if $w_{1} \geq P(S(w))$ and that $\hat{\pi}_{1}\left(w_{1}, w\right)=(P(S(w))$ $\left.-w_{1}\right) S(w)$ if $w \leq w_{1} \leq P\left((S(w))\right.$. Hence, the slope of $\hat{\pi}_{1}$ is $-S(w)$ whenever it is positive. On the other hand, LemmaA.2 also shows that $d \pi_{1} / d w_{1}\left(w_{1}, w\right)>-S(w)$ 


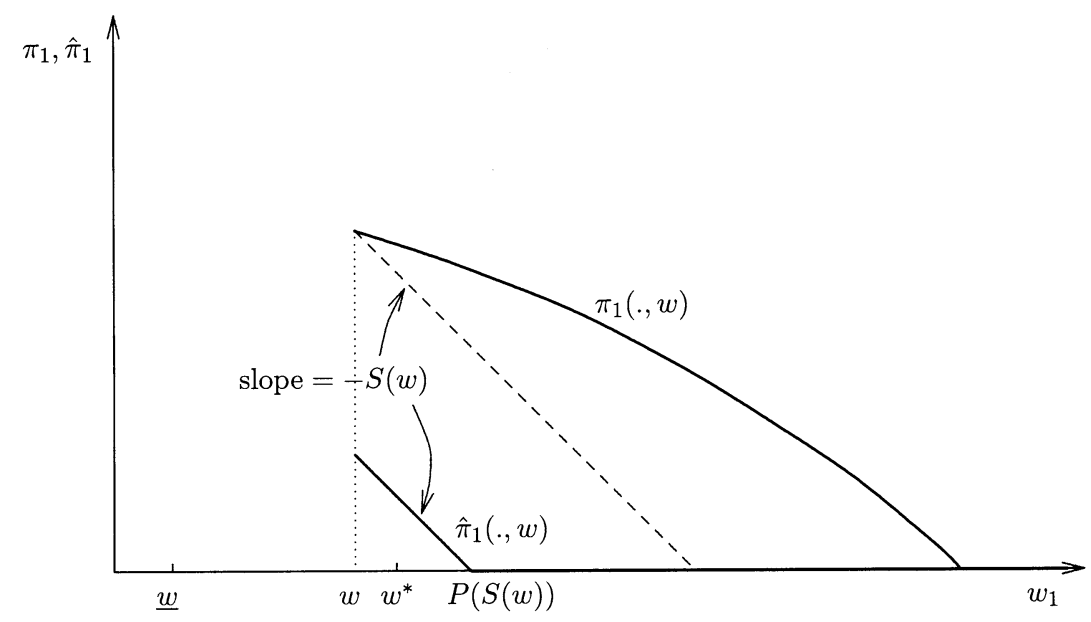

Figure 2. Firm 1's profit at the Cournot Nash equilibrium $\left(\pi_{1}\right)$ and at an excess labour demand $\left(\hat{\pi}_{1}\right)$

whenever $\pi_{1}$ is positive. Therefore, firm 1's profit at the Cournot Nash equilibrium $\pi_{1}\left(w_{1}, w\right)$ is higher than its profit when it deviates to an excess labour demand $\hat{\pi}_{1}\left(w_{1}, w\right)$ for all wages $w_{1}>w$ if and only if

$$
\begin{aligned}
\pi_{1}(w, w) & =\left(P\left(\Psi^{-1}(w)\right)-w\right) \frac{\Psi^{-1}(w)}{n} \geq(P(S(w))-w) S(w) \\
& =\hat{\pi}_{1}(w, w)
\end{aligned}
$$

see Figure 2. Condition (8) is clearly fulfilled in some neighborhood of $w=w^{*}$ since $\hat{\pi}_{1}\left(w^{*}, w^{*}\right)=0<\pi_{1}\left(w^{*}, w^{*}\right)$ and since both $\pi_{1}$ and $\hat{\pi}_{1}$ are continuous. (8) is however not fulfilled in a neighborhood of the Cournot Nash market clearing wage $w=\underline{w}$ at which $\Psi^{-1}(\underline{w})=S(\underline{w})$. At this wage (and at wages close to it) it is profitable for any firm to raise the wage slightly, to force other firms out of the labour market by employing all their labour supply $S(w)$, and thus to corner the output market. The cost of taking up all labour supply is a fall in the resulting output price, and this cost is lower than the gain of cornering the output market only if unemployment at $w$ is low enough.

We can conclude that there exists a $\tilde{w} \in\left(\underline{w}, w^{*}\right)$ such that (8) holds with equality at $\tilde{w}$ and holds strictly at any $w>\tilde{w}$. Therefore, if $w_{1}>w \in\left[\tilde{w}, w^{*}\right]$, the Cournot Nash equilibrium labour demand is a best response for firm 1 .

Proposition 3. There exists a $\tilde{w} \in\left(\underline{w}, w^{*}\right)$ such that if firms set wages $w_{1}>$ $w_{2}=\ldots=w_{n}=w \in\left[\tilde{w}, w^{*}\right]$ at stage I, there exists a Nash equilibrium of the stage II game in which labour demands and employment levels are the Cournot Nash equilibrium strategies $J_{1}=\ell_{1}, J_{i}=\ell, i>1$, and in which firm 1 makes profit $\pi_{1}\left(w_{1}, w\right)<\pi_{1}(w, w)$. In particular, overbidding from $w_{1}=\ldots=w_{n}=w$ is unprofitable.

Propositions 1-3 together prove the existence of involuntary unemployment equilibria: 


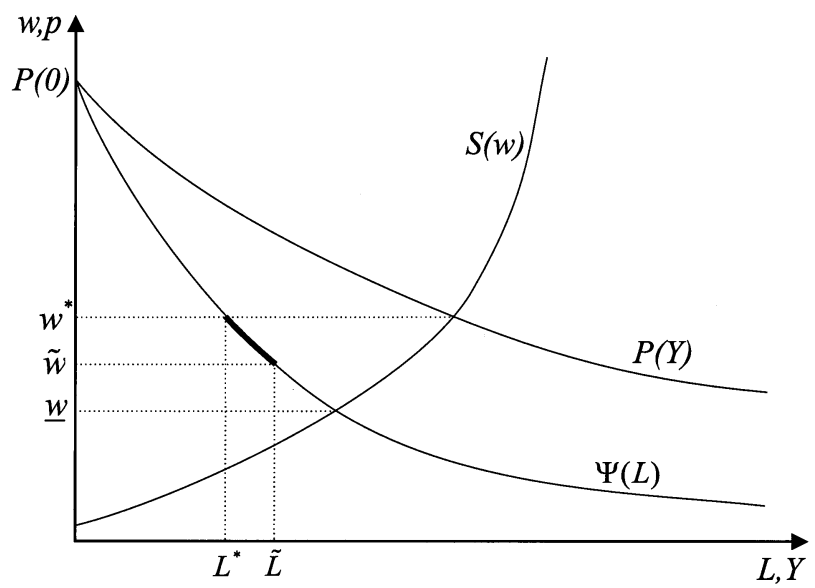

Figure 3. The bold curve shows wages and aggregate employment levels in the unemployment equilibria of Theorem 1

Theorem 1. There exists a continuum of symmetric equilibria with involuntary unemployment and positive profits in which firms set wages $w_{1}=\ldots=w_{n}=$ $w \in\left[\tilde{w}, w^{*}\right]$ and in which aggregate employment levels are $\Psi^{-1}(w)<S(w)$.

Theorem 1 characterizes all symmetric pure strategy equilibria of this game that involve involuntary unemployment. At wages above the Walrasian wage $w^{*}$, firms find undercutting profitable. At wages below $\tilde{w}$, a firm finds it profitable to overbid and to take the whole market. Note in particular that the lowest unemployment wage $\tilde{w}$ exceeds the wage $\underline{w}$ where Cournot labour demand equals labour supply. At this wage (and at wages nearby) firms want to raise the wage slightly to attract all labour and to attain a monopoly in the output market. ${ }^{16}$ Figure 3 illustrates the unemployment equilibria of Theorem 1 .

\section{The full employment equilibrium}

We ask now whether there also exist symmetric equilibria with full employment, and we start again with the analysis of the stage II game after equal wages $w_{1}=$ $\ldots=w_{n}=w$ at stage I. Clearly, if this wage is larger than the competitive wage, firms would not want to employ all labour supply at this wage, since then profits would be negative and each firm would prefer not to produce at all. On the other hand, for any $w \leq w^{*}$ there exists a Nash equilibrium of the stage II game with full employment in which all firms signal labour demands $J_{i}=S(w) /(n-1)$, $i=1, \ldots, n$. No firm wants to deviate from this labour demand since there is an excess demand for labour even if one firm deviates to zero labour demand. Hence, aggregate employment stays constant at $S(w)$ and the resulting output price remains

16 Note the similarity of this argument to the one given by Stahl (1988) and Yanelle (1989) to show that the Walrasian outcome is not an equilibrium of the double-market Bertrand game with inelastic demand. 
at $P(S(w)) \geq w$. Since all firms' employment constraints are $S(w) / n$ (by (4)), each firm's profit function is non-decreasing for $J<S(w) / n$ and constant for $J \geq S(w) / n$. In particular, $J=S(w) /(n-1)$ is a best response. The bold part of the supply curve in Figure 1 shows the stage II full employment Nash equilibria after equal wages at stage I.

It is, however, immediate to see that no wage below the competitive wage followed by a full employment stage II continuation can be a subgame perfect Nash equilibrium. Any firm (say firm 1) could raise the wage to some $w_{1}>w$, employ all labour supply at that wage so that residual labour supply to the other firms would be zero and firm 1's profit would be $\left(p\left(P\left(w_{1}\right)\right)-w_{1}\right) S\left(w_{1}\right)$ which is strictly greater than firm 1's profit at the symmetric full employment equilibrium $(P(S(w))-w) S(w) / n$ when $w_{1}$ is close to $w$. Therefore, the only candidate for a symmetric full employment equilibrium is the competitive wage, and it turns out that it is indeed an equilibrium. ${ }^{17}$

Theorem 2. The unique symmetric full employment equilibrium is the zero-profit competitive equilibrium.

Proof. As in the proof of Theorem 1, we show that neither undercutting nor overbidding by firm 1 is profitable. If firm 1 undercuts, the same stage II Nash equilibrium as in Proposition 2 would result in zero profits for firm 1, and thus undercutting is unprofitable. If firm 1 overbids to $w_{1}>w^{*}$, there exists a Nash equilibrium of the stage II game in which $J_{1}=0$ and $J_{i}=S\left(w^{*}\right) /(n-2), i>1$. Clearly, $J_{i}=S\left(w^{*}\right) /(n-2)$ is a best response to $J_{1}=0$ and $J_{k}=S\left(w^{*}\right) /(n-2), k>1$, $k \neq i$, by the same argument as in the proof of Proposition 2 (firms $i>1$ are now the low wage firms, but since $J_{1}=0$, the argument is the same). Now suppose that firm 1 deviates to some $J_{1}>0$. Since there is an excess labour demand at $w^{*}$, total employment would be $S\left(w^{*}\right)$ as long as $J_{1} \leq S\left(w^{*}\right)$. Hence, if $0<J_{1} \leq S\left(w^{*}\right)$ firm 1's profit $\pi_{1}=\left(P\left(S\left(w^{*}\right)\right)-w_{1}\right) J_{1}=\left(w^{*}-w_{1}\right) J_{1}$ would be negative. If firm 1 deviates to $J_{1}>S\left(w^{*}\right)$, residual labour supply at $w^{*}$ would be zero, and thus firm 1's profit would be $\pi_{1}\left(\ell_{1}\right)=\left(P\left(\ell_{1}\right)-w_{1}\right) \ell_{1}$ where $\ell_{1}=\min \left(J_{1}, S\left(w_{1}\right)\right)$. $\pi_{1}$ is however decreasing in $\ell_{1}>S\left(w^{*}\right)$ since

$$
\begin{aligned}
\pi_{1}^{\prime}\left(\ell_{1}\right) & =\operatorname{MR}\left(\ell_{1}\right)-w_{1}<\operatorname{MR}\left(S\left(w^{*}\right)\right)-w_{1}<P\left(S\left(w^{*}\right)\right)-w_{1} \\
& =w^{*}-w_{1}<0 .
\end{aligned}
$$

Therefore, all $J_{1}>0$ lead to negative profits for firm 1 , and so $J_{1}=0$ is a best response.

Theorems 1 and 2 characterize all symmetric equilibria of the oligempory game. Although a full employment equilibrium exists, there are reasons which point towards involuntary unemployment as the more natural outcome. First, the full employment equilibrium is payoff dominated by all involuntary unemployment equilibria of Theorem 1 . In fact the involuntary unemployment equilibrium at the symmetric wage $\tilde{w}$ has highest profits and payoff dominates all other equilibria.

17 This result does not extend to $n=2$ firms. In fact, it can be shown that overbidding of the competitive wage leads to positive (expected) profits for the overbidding firm in any (possibly mixed strategy) Nash equilibrium continuation of the stage II game. 
Second, the competitive equilibrium is in a certain sense unstable since all wage deviations at the first stage produce zero profits for the deviator, and since also all labour demand deviations at the second stage lead to zero profits as well. Thus, best responses at the first and second stage of the equilibrium path are not unique, and all deviations from the equilibrium strategies are not costly. In contrast, our unemployment equilibria have unique best responses at each stage along the equilibrium path. Propositions 2 and 3 show that deviations from the symmetric wage at stage I lead to strictly lower profits, Proposition 1 shows that the Cournot Nash equilibrium labour demands are the unique best responses at stage II, and also the stage III and stage IV equilibrium strategies (5) and (6) are unique best responses (see Madden, 1998, for the stage IV game). Hence, any deviation from the equilibrium path would be costly, and therefore our unemployment equilibria are strict along the equilibrium path (see Güth and Ritzberger, 1998).

\section{5 "Competitive" limits}

To illustrate the role of imperfect competition in the product and labour market for our results, we examine how the unemployment equilibria depend on various measures of market power: the number of firms, the elasticity of product demand, and the elasticity of labour supply. We denote by $L^{*}=\Psi^{-1}\left(w^{*}\right)$ and by $\tilde{L}=\Psi^{-1}(\tilde{w})$ the lowest (highest, resp.) equilibrium employment levels in the unemployment equilibria of Theorem 1 (see Fig. 3).

Consider first the limit $n \rightarrow \infty$. It is obvious from the definition that the marginal revenue function $\Psi(Y)$ converges uniformly to the inverse demand function $P(Y)$ on any compact domain. Therefore, $\underline{w}$ (and thus $\tilde{w}$ ) converge to the Walrasian wage, and employment levels $L^{*}$ and $\tilde{L}$ converge to the Walrasian employment level $S\left(w^{*}\right)$. Thus, we confirm the standard result that the Walrasian outcome emerges as the unique equilibrium in the limit of an infinite number of firms.

Proposition 4. If $n \rightarrow \infty$, then prices, wages, employment and output levels in all unemployment equilibria of Theorem 1 converge to their Walrasian values.

We turn now to the role of demand and supply elasticities. For tractability of the analysis, it is convenient to use a parametric example with isoelastic demand and supply curves. Suppose that output demand is $D(p)=p^{-\alpha}$ with $\alpha>1$, and labour supply is $S(w)=\min \left(w^{\beta}, \bar{S}\right), \beta \geq 0, \bar{S}>1$. The Walrasian equilibrium wage (=price) is given by $w^{*}=p^{*}=1$ with employment/output level $D\left(p^{*}\right)=$ $S\left(w^{*}\right)=1$. The Cournotian marginal revenue function $\Psi$ is

$$
\Psi(L)=L^{-1 / \alpha}\left(1-\frac{1}{n \alpha}\right) .
$$

Theorem 1 implies that for wages in the interval $\left[\tilde{w}, w^{*}\right]$ there are unemployment equilibria with employment levels $\Psi^{-1}(w)$ and unemployment rates $u=1-$ $\Psi^{-1}(w) / S(w)$. In particular, the (highest) equilibrium unemployment rate at the Walrasian wage is

$$
u^{*}=1-\left(1-\frac{1}{n \alpha}\right)^{\alpha} .
$$


According to the proof of Proposition 3, the lowest equilibrium wage $\tilde{w}$ is determined by equation (8) which, after substituting for the corresponding unemployment rate $\tilde{u}$, turns out to be

$$
n \alpha-1+\frac{1}{n}(1-\tilde{u})=n \alpha(1-\tilde{u})^{1 / \alpha} .
$$

It is easy to see that this equation has a unique solution $\tilde{u}$ in the interval $\left(0, u^{*}\right)$. All unemployment rates in the interval $\left[\tilde{u}, u^{*}\right]$ are attained in the unemployment equilibria of Theorem 1 . What happens to equilibrium unemployment if either the elasticity of product demand $(\alpha)$ or the elasticity of labour supply $(\beta)$ converges to infinity?

Consider first the limit of a "competitive" labour market $(\beta \rightarrow \infty)$. Graphically, in Figure 3, labour supply approaches a horizontal line at $w^{*}=1$, so that $\underline{w}$ and $\tilde{w}$ must converge to the Walrasian wage $w^{*}=1$. On the other hand, equations (9) and (10) reveal that unemployment rates in the unemployment equilibria do not depend on $\beta$. Thus, unemployment does not disappear in the limit case of a perfectly elastic labour supply. Of course, in the limit $\beta=\infty$ unemployment becomes voluntary as workers are indifferent between working or being unemployed.

Consider now the limit of a "competitive" product market $(\alpha \rightarrow \infty)$. Graphically, both the inverse demand curve $P$ and the Cournotian marginal revenue curve $\Psi$ become horizontal at $p^{*}=1$. Therefore, all equilibrium prices and wages converge to their Walrasian value $w^{*}=p^{*}=1$. However, unemployment remains strictly positive in all unemployment equilibria: $u^{*}$ converges to $u_{\infty}^{*}=1-e^{-1 / n}$, whereas $\tilde{u}$ converges to the unique solution $\tilde{u}_{\infty} \in\left(0, u_{\infty}^{*}\right)$ of the equation

$$
1+n \ln (1-u)=\frac{1-u}{n} .
$$

Hence, unemployment persists in the limit of a perfectly elastic product demand, whereas wages and prices converge to their Walrasian values. ${ }^{18}$ One may wonder whether even the oligopsony model in which firms take the competitive price $p^{*}=1$ as given (i.e. our model without stage IV) has unemployment equilibria. Indeed it turns out that firms setting the Walrasian wage at stage I and rationing labour supply to any arbitrary level at stage II is a subgame perfect equilibrium; any attempt to undercut can be punished by an employment expansion of the rivals. However, all these equilibria involve zero profits, and thus they do not payoff dominate the competitive equilibrium. More importantly, these unemployment equilibria are not robust to decreasing returns, as has been shown in an earlier version of this paper (Kaas and Madden, 1999). In contrast, the unemployment equilibria of the oligempory (i.e. oligopsony and oligopoly) model are robust to decreasing returns, as will be discussed in the next section.

\section{Robustness}

We explore now the robustness of our main results to variations of the model in Section 2.

18 Compare this limit result with the limit $n \rightarrow \infty$. In both cases, the marginal revenue curve converges uniformly to the inverse demand curve. Whereas this implies Walrasian convergence for $n \rightarrow \infty$, there is no Walrasian convergence for $\alpha \rightarrow \infty$, since both curves become horizontal in the limit. 
So far, we have assumed a constant returns to scale production function. The reason why firms did not undercut an involuntary unemployment equilibrium wage was that the other high-wage firms would expand labour demand forcing the undercutter to zero trade and profits. A similar response supports the classic, single market Bertrand paradox equilibrium under constant returns, an equilibrium which disappears under decreasing returns. In our model, in contrast, we can show that the main features have no such knife-edge dependency on constant returns. Specifically, if production functions exhibit a small amount of decreasing returns, there continues to be a continuum of involuntary unemployment equilibria which payoff dominate any symmetric full employment equilibria. The full argument is lengthy and technical, so we merely state the result - a proof and discussion is available on request from the authors.

We consider decreasing returns production functions $f\left(\ell_{i}\right)$ which belong to the family $F(\sigma), \sigma \in[0,1)$, of twice continuously differentiable concave functions defined on $[0, \bar{S}]$ where $f(0)=0$ and $f^{\prime}\left(\ell_{i}\right) \in[1-\sigma, 1+\sigma]$ for all $\ell_{i} \in[0, \bar{S}]$. For $f \in F(\sigma), f\left(\ell_{i}\right) \in\left[(1-\sigma) \ell_{i},(1+\sigma) \ell_{i}\right]$ and so the output level and the marginal product of labour are "uniformly close" to their unit constant returns values if $\sigma$ is "small". With $w^{*}$ and $\underline{w}$ as defined earlier (see Fig. 1), the result is:

Theorem 3. There exists some $\sigma^{*}>0$ and some $w_{a}<w_{b}$ where $w_{a}, w_{b} \in$ $\left(\underline{w}, w^{*}\right)$, such that if the production function $f\left(\ell_{i}\right)$ belongs to the family $F\left(\sigma^{*}\right)$ then;

(a) there exists a continuum of symmetric equilibria with involuntary unemployment and positive profits in which firms set wages $w_{1}=\ldots=w_{n}=w \in$ $\left[w_{a}, w_{b}\right]$,

(b) for firms, the equilibria in (a) payoff dominate any symmetric equilibrium with full employment.

How robust are our results to the specification of rationing? First, our results do not depend on the assumption that labour supply is efficiently rationed. If we assume random rationing instead, the residual supply at the second highest wage $w^{L}<w^{H}$ would be (with $J^{H}<S\left(w^{H}\right)$ denoting labour demand at the highest wage) (1 $\left.J^{H} / S\left(w^{H}\right)\right) S\left(w^{L}\right)$. Residual supply is thus larger than under efficient rationing. The undercutting argument would be exactly the same as under efficient rationing, since high wage firms' labour demand exceeds supply, leaving zero residual supply to the undercutting firm again. If firm 1 overbids the equilibrium wage and deviates from the Cournot Nash labour demand to above such that low wage firms are rationed, the resulting output price would be lower than under efficient rationing since residual labour supply at the low wage is higher. Hence, firm 1's profit would not be greater than its profit under efficient rationing, $\hat{\pi}_{1}\left(w_{1}, w\right)$, if it deviates to an excess labour demand, and therefore the Cournot Nash labour demand is again a best response of the overbidding firm 1 to the Cournot Nash labour demands of the low wage firms. On the other hand, non-manipulability of rationing is a decisive feature for our results. Some other formulations of rationing schemes in Bertrand games specify the firms' rationing to be proportional and thus manipulable (see, e.g., Allen and Hellwig, 1986). When firms are proportionally rationed, labour allocated 
to firms would be, instead of (3), given by $\ell_{i}=\min \left(J_{i}, S \cdot J_{i} /\left(\sum_{k=1}^{m} J_{k}\right)\right)$. Hence, any firm could get all (residual) labour supply by raising its labour demand to infinity, in particular it could attract all workers from other firms paying the same wage. We believe that such a feature would not be a credible description of the matching of jobs and workers in the labour market. It would also lead to serious non-existence problems in several stage II subgames.

Our results depend crucially on some specifications of the timing of the game, while others may be varied. It is decisive to assume that firms commit to wages before they decide on employment and also that they decide on employment before they set prices. If firms decide either wages and employment or employment and prices simultaneously, our undercutting argument breaks down. However, other timing assumptions may be changed. If firms decided on employment and production simultaneously at stage II and then on prices at stage III, the game's equilibria would be the same, since firms would still set $y_{i}=\ell_{i}$ in any stage II equilibrium. Furthermore, if firms decided on production and prices simultaneously after employment, the stage III game would be a simultaneous Bertrand-Edgeworth game with capacities $\left(\ell_{1}, \ldots, \ell_{n}\right)$ in which costs are sunk. Because demand is elastic, the unique Nash equilibrium of this game would again be given by (5) and (6) irrespective of the way demand is rationed.

As in Stahl (1988), our model is partial equilibrium, and output demand and labour supply schedules are not explicitly derived from utility maximizing workers/consumers, unlike in the models of Roberts (1987), Jones and Manuelli (1992) or Drèze (1997). However, it is straightforward to integrate our model in a multi-sector general equilibrium model in the spirit of Blanchard and Kiyotaki (1987) in which a continuum of consumers demand consumption goods from all sectors, but supply labour in only one sector. If consumers receive profit income from various sectors and if the number of sectors is large, there are no income feedbacks on the labour supply and output demand functions of each sector. Hence, the equilibrium in each sector is as in the partial equilibrium model, and if firms in all sectors coordinate on unemployment equilibria, the general equilibrium also involves unemployment.

\section{Conclusions}

Involuntary unemployment can be easily explained as a disequilibrium phenomenon emanating from ad hoc nominal or real rigidities. To provide an equilibrium account for involuntary unemployment is a more difficult matter. Efficiency wages provide perhaps the best-known explanation. Here we have taken up the theme from another well-known story (Roberts, 1987, 1989), where a multi-stage game, in which constant returns firms possess labour and output market power, produces zero-profit equilibria with involuntary unemployment and with full employment. The involuntary unemployment equilibria are generated by a coordination failure arising from the assumed simultaneity of labour supply and output demand offers at the second stage of the game after wages and prices have been set at the first stage. With first stage wage and price commitment, but variations in the subsequent timing of demand and supply offers, Jones and Manuelli (1992) find that the involuntary unemployment disappears from equilibrium, an outcome also found in the related 
model of Stahl (1988). Our model differs from these predecessors in that firms make labour demand decisions before they have to commit to output prices, and these employment decisions then have a strategic influence on prices.

Our results also differ markedly from the previous literature - there exists a continuum of positive profit, involuntary unemployment equilibria which payoff dominate full employment equilibria, and this conclusion holds under constant returns and under (small amounts of) decreasing returns. The mechanism supporting the equilibrium involuntary unemployment is essentially Bertrand, but quite different from that of Roberts. Firms do not undercut the wage since they fear that the other firms would each expand their labour demand so as to leave the undercutter with zero employment and profit; and it is optimal for each of the high-wage firms to expand labour demand if the others do since, under constant or near constant returns, the expansion has a negligible impact on output price. The paper thus claims to provide a new and robust explanation for involuntary unemployment as an equilibrium phenomenon.

\section{Appendix}

Lemma A.1. If there are $m$ firms setting the same wage, if (residual) labour supply at this wage is $S$, and if the labour demands of firms $2, \ldots, m$ are all equal to $J$, then firm 1 is rationed according to $\ell_{1}=\min \left(J_{1}, c(J, \ldots, J, S)\right)$ where the employment constraint is

$$
c(J, \ldots, J, S)=\max \left(\frac{S}{m}, S-(m-1) J\right) .
$$

Proof. First consider $J>S / m$. If firm 1 signals $J_{1}=J$, by symmetry all firms would be rationed to $\ell_{i}=S / m, i=1, \ldots, m$. Thus, firm 1's employment constraint is $c(J, \ldots, J, S)=S / m>S-(m-1) J$. Second consider $J<S / m$. Then $c(J, \ldots, J, S) \geq S-(m-1) J$, since otherwise firm 1 would be rationed if it signalled $J_{1}=S-(m-1) J$ which is impossible since the rationing scheme is assumed to be frictionless. Now suppose $c(J, \ldots, J, S)>S-(m-1) J$. If then firm 1 signals $J_{1}=c(J, \ldots, J, S)$ it gets $\ell_{1}=J_{1}$ and by symmetry all other firms are rationed to $\ell=\left(S-J_{1}\right) /(m-1)<J$. In particular, if firm 2 deviated to the higher labour demand $J_{2}=J_{1}>J$ it would still be rationed to $\tilde{\ell}_{2}=\ell<J$ (because of non-manipulability), and because of symmetry firm 1 must then be rationed to $\tilde{\ell}_{1}=\tilde{\ell}_{2}=\ell$, too. All other firms signalling labour demands $J$ get some $\tilde{\ell} \leq J$. But this contradicts the assumption that the rationing scheme is frictionless since total employment is $\tilde{\ell}_{1}+\tilde{\ell}_{2}+(m-2) \tilde{\ell}<m J<S$ while total demand is $J_{1}+J_{2}+(m-2) J>m J$. Therefore we must have $c(J, \ldots, J, S)=S-(m-1) J>S / m$. Finally, the case $J=S / m$ follows from continuity of $\mathrm{c}($.$) .$

Lemma A.2. Suppose that $w_{1}>w_{2}=\ldots=w_{n}>\underline{w}$. Then there exists a Cournot Nash equilibrium $\ell_{1} \geq 0, \ell_{2}=\ldots=\ell_{n}=\ell>0$ such that $\ell_{1}<S\left(w_{1}\right)$ and $(n-1) \ell<S(w)-\ell_{1}$. Firm 1's profit in this Cournot Nash equilibrium $\pi_{1}\left(w_{1}, w\right)$ is strictly decreasing in $w_{1}$ whenever it is positive. Moreover, $\frac{d \pi_{1}}{d w_{1}}\left(w_{1}, w\right)>-S(w)$. 
Proof. Since profit functions are strictly concave by assumption $(1), \ell_{1}, \ell_{2}=\ldots=$ $\ell_{n}=\ell$ is a Cournot Nash equilibrium (CNE) if the first order conditions

$$
\begin{gathered}
P^{\prime}(L) \ell_{1}+P(L) \leq w_{1}, \ell_{1} \geq 0, \ell_{1}\left(P^{\prime}(L) \ell_{1}+P(L)-w_{1}\right)=0 \\
P^{\prime}(L) \ell+P(L)=w, \ell>0
\end{gathered}
$$

are fulfilled, where $L=\ell_{1}+(n-1) \ell$. Clearly, an interior CNE $\left(\ell_{1}>0\right)$ has to satisfy

$$
\Psi(L)=P^{\prime}(L) \frac{L}{n}+P(L)=\frac{w_{1}+(n-1) w}{n}
$$

and

$$
\begin{gathered}
\ell=\ell\left(w_{1}, w\right)=\frac{w-P(L)}{P^{\prime}(L)}>0 \quad \text { and } \\
\ell_{1}=\ell_{1}\left(w_{1}, w\right)=\frac{w_{1}-P(L)}{P^{\prime}(L)}>0 .
\end{gathered}
$$

A solution to (13) exists whenever $\left(w_{1}+(n-1) w\right) / n<P(0)=\Psi(0)$ and $\ell$ is then always positive because $w<\left(w_{1}+(n-1) w\right) / n=\Psi(L)<P(L)$. If $\ell_{1}\left(\tilde{w}_{1}, w\right)=0$ for some $\tilde{w}_{1}>w$, then for all $w_{1} \geq \tilde{w}_{1}$ there exists a CNE where $\ell_{1}=0$ and where $\ell$ is uniquely determined by (12).

Whenever the CNE is interior, differentiation of (13) implies that

$$
\frac{d L}{d w_{1}}=\frac{1}{P^{\prime \prime}(L) L+P^{\prime}(L)(1+n)}<0
$$

(the denominator is negative because of (1)). Differentiation of (11) yields

$$
\frac{d \ell_{1}}{d w_{1}}=\frac{1}{P^{\prime}(L)} \cdot \frac{P^{\prime \prime}(L)\left(L-\ell_{1}\right)+P^{\prime}(L) n}{P^{\prime \prime}(L) L+P^{\prime}(L)(1+n)}
$$

which is also negative because of (1) (the numerator is clearly negative when $P^{\prime \prime}(L) \leq 0$; when $P^{\prime \prime}(L)>0$, we have $P^{\prime \prime}(L)\left(L-\ell_{1}\right)+n P^{\prime}(L)<P^{\prime \prime}(L) L+$ $\left.2 P^{\prime}(L)<0\right)$. (14) and (15) imply that

$$
\begin{gathered}
\ell_{1}\left(w_{1}, w\right)<\ell_{1}(w, w)<S(w) \leq S\left(w_{1}\right), \\
\ell_{1}\left(w_{1}, w\right)+(n-1) \ell\left(w_{1}, w\right)<\ell_{1}(w, w)+(n-1) \ell(w, w)<S(w) .
\end{gathered}
$$

Firm 1's profit $\pi_{1}\left(w_{1}, w\right)=\left(P(L)-w_{1}\right) \ell_{1}$ is decreasing in $w_{1}$ when the CNE is interior since

$$
\frac{d \pi_{1}}{d w_{1}}=-\frac{\ell_{1}}{P^{\prime \prime}(L) L+P^{\prime}(L)(1+n)}\left(P^{\prime \prime}(L)\left(2 L-\ell_{1}\right)+P^{\prime}(L) 2 n\right)<0
$$

(the term in the bracket is clearly negative when $P^{\prime \prime}(L) \leq 0$; when $P^{\prime \prime}(L)>0$ we have $\left.P^{\prime \prime}(L)\left(2 L-\ell_{1}\right)+P^{\prime}(L) 2 n<2\left(P^{\prime \prime}(L) L+2 P^{\prime}(L)\right)<0\right)$.

Finally, we show that $\frac{d \pi_{1}}{d w_{1}}>-L>-S(w)$. This amounts to showing that

$$
P^{\prime \prime}(L)\left(2 L-\ell_{1}\right)+P^{\prime}(L) 2 n>\frac{L}{\ell_{1}}\left(P^{\prime \prime}(L) L+P^{\prime}(L)(1+n)\right) .
$$


From (14) and (15) it follows that $d L / d w_{1}>d \ell_{1} / d w_{1}$, and thus $L / \ell_{1} \geq n$ since $L(w, w) / \ell_{1}(w, w)=n$. Hence, (16) follows if

$$
P^{\prime \prime}(L)\left(2 L-\ell_{1}\right)+P^{\prime}(L) 2 n>n\left(P^{\prime \prime}(L) L+P^{\prime}(L)(1+n)\right)
$$

or if

$$
P^{\prime \prime}(L)\left(\frac{(n-2) L+\ell_{1}}{n-1}\right)+P^{\prime}(L) n<0 .
$$

But this last condition follows again from $(1)$ and $\left((n-2) L+\ell_{1}\right) /(n-1)<L$.

\section{References}

Allen, B., Hellwig, M.: Bertrand-Edgeworth oligopoly in large markets. Review of Economic Studies 53, 175-204 (1986)

Beckmann, M.: Edgeworth-Betrand duopoly revised. In: Henn, R. (ed.) Research-Verfahren III, Vol. 80, pp. 55-68. Meisenheim: Anton Hein 1965

Bénassy, J.-P.: The economics of market disequilibrium. New York: Academic Press 1982

Bewley, T. F.: Why not cut pay? European Economic Review 42, 459-490 (1998)

Blanchard, O. J., Kiyotaki, N.: Monopolistic competition and the effects of aggregate demand. American Economic Review 77, 647-666 (1987)

Böhm, V., Maskin, E., Polemarchakis, H., Postlewaite, A.: Monopolistic quantity rationing. Quarterly Journal of Economics 98, 189-197 (1983)

Dixon, H., Rankin, N.: Imperfect competition and macroeconomics: a survey. Oxford Economic Papers 46, 171-199 (1994)

Dobson, P. W.: Horizontal and vertical market structures. Unpublished Ph.D. dissertation, University of London (1990)

Drèze, J. H.: Walras-Keynes equilibria coordination and macroeconomics. European Economic Review 41, 1735-1762 (1997)

Dufwenberg, M., Kirchsteiger, G.: Reciprocity and wage undercutting. European Economic Review 44, 1069-1078 (2000)

Fehr, E., Kirchsteiger, G., Riedl, A.: Does fairness prevent market clearing? An experimental investigation. Quarterly Journal of Economics 108, 437-460 (1993)

Fehr, E., Kirchsteiger, G., Riedl, A.: Gift exchange and reciprocity in competitive experimental markets. European Economic Review 42, 1-34 (1998)

Fudenberg, D., Tirole, J.: Game theory. Cambridge, MA: MIT Press 1991

Funk, P.: Bertrand and Walras equilibria in large economies. Journal of Economic Theory 67, 436-466 (1995)

Gaygisiz, E., Madden, P.: Macroeconomic coordination failure under oligempory. Economic Theory 20, 93-112 (2002)

Güth, W., Ritzberger, K.: On durable goods monopolies and the coase-conjecture. Review of Economic Design 3, 215-236 (1998)

Heal, G.: Rational rationing and increasing returns: an example. Economics Letters 8, 19-27 (1981)

Jones, L. E., Manuelli, R. E.: The coordination problem and equilibrium theories of recessions. American Economic Review 82, 451-471 (1992)

Kaas, L., Madden, P.: Equilibrium involuntary unemployment under oligempory. Economics Series 68 , Institute for Advanced Studies, Vienna (1999)

Kreps, D. M., Scheinkman, J.A.: Quantity precommitment and Bertrand competition yield Cournot outcomes. Bell Journal of Economics 14, 326-338 (1983)

Madden, P.: Elastic demand, sunk costs and the Kreps-Scheinkman extension of the Cournot model. Economic Theory 12, 199-212 (1998)

Madden, P., Silvestre, J.: Imperfect competition and fixprice equilibria when goods are gross substitutes. Scandinavian Journal of Economics 93, 479-494 (1991) 
Madden, P., Silvestre, J.: Imperfect competition and fixprice equilibria under consumer aggregation and net substitutes. Scandinavian Journal of Economics 94, 103-111 (1992)

Nichol, A. J.: Review of "A theoretical analysis of imperfect competition with special applications to the agricultural industries" by W. H. Nicholls. Journal of Political Economy 51, 82-84 (1943)

Osborne, M. J., Pitchik, C.: Price competition in a capacity-constrained duopoly. Journal of Economic Theory 38, 238-260 (1986)

Roberts, J.: An equilibrium model with involuntary unemployment at flexible competitive prices and wages. American Economic Review 77, 856-874 (1987)

Roberts, J.: Involuntary unemployment and imperfect competition: a game theoretic macro model. In: Feiwell, G. (ed.) The economics of imperfect competition and employment: Joan Robinson and beyond, pp. 146-165. London: Macmillan 1989

Silvestre, J.: The market-power foundations of macroeconomic policy. Journal of Economic Literature 31, 105-141 (1993)

Stahl, D. O.: Bertrand competition for inputs and Walrasian outcomes. American Economic Review 78, 189-201 (1988)

Yanelle, M.-O.: The strategic analysis of intermediation. European Economic Review 33, 294-301 (1989) 